Hydrology and Earth System Sciences, 5(4), 554-562 (2001) C EGS

\title{
The HYDROMED model and its application to semi-arid Mediterranean catchments with hill reservoirs 2: Rainfall-runoff model applications to three Mediterranean hill reservoirs
}

\author{
R. Ragab ${ }^{1}$, D. Moidinis ${ }^{1}$, J. Albergel ${ }^{2}$, J. Khouri $^{3}$, A. Drubi $^{3}$ and S. Nasri ${ }^{4}$ \\ ${ }^{1}$ Centre for Ecology and Hydrology, Wallingford, OX10 8BB, UK \\ ${ }^{2}$ IRD, France (IRD mission in Tunisia) \\ ${ }^{3}$ ACSAD, Syria \\ ${ }^{4}$ INGREF, Tunisia \\ E-mail for corresponding author: Rag@ceh.ac.uk
}

\begin{abstract}
The objective of this work was to assess the performance of the newly developed HYDROMED model. Three catchments with hill reservoirs were selected. They are El-Gouazine and Kamech in Tunisia and Es Sindiany in Syria. The rainfall, the spillway flow and volume of water in the reservoirs were used as input to the model. Events that generated spillway flow were preferred for calibration. The results confirmed that the HYDROMED model is capable of reproducing the runoff volume at all the three sites. In calibrating single events, the model performance was high as measured by the Nash-Sutcliffe criterion for goodness of fit. In some events this value was as high as $98 \%$. In simulation mode, the highest Nash-Sutcliffe criterion value was close to $70 \%$ in the El-Gouazine and Kamech catchments and close to 50\% in the Es Sindiany catchment. Given the limited information available, especially on the unrecorded releases in the three catchments, the hydrological impact of site geology (e.g. Kamech), the unrecorded operator intervention during the spillway flow (e.g Es Sindiany) and other unaccounted factors (e.g siltation, evaporation, etc.), these results are by and large very encouraging. However, they could be further improved as and when more information on the unrecorded parameters becomes available. Additionally, the results of this work highlighted the need for long term records with a large number of significant events that are able to generate spillway flow to obtain more consistent and reliable parameter values. It also highlights the need for more accurately recorded releases for irrigation and other uses. As these results are encouraging, more tests on those three and other sites are planned.
\end{abstract}

Keywords: HYDROMED, rainfall-runoff model, Mediterranean, conceptual model

\section{Introduction}

The limited water resources of the Mediterranean region and the continuing alarming level of population growth requires an efficient water supply and demand management system. In many cases, increasing water supply requires investment in building dams and surface reservoirs. Rainfall harvesting to small lakes is an attractive means to increase water supply and a solution to increase water supply in Mediterranean coastal regions. Rainfall harvesting to mountain lakes is a well established practice in the region. However, the newly constructed reservoirs are based on better knowledge of the hydrology and geology and are built using better technology. The waters from these reservoirs are now widely used in the region to produce food for the adjacent communities. Irrigation of field crops and fruit trees, fishing, leisure, tourism, domestic use, etc. are different benefits of these small hill reservoirs. Many of the reservoirs that supply the irrigation systems rely on less than a week of rainfall occurring every year.

Predicting or estimating the runoff into hill reservoirs can be a useful tool for water management. Striking a balance between the supply and demand of the different users would depend on a reliable estimate of water supply. In that respect, simple conceptual Rainfall-Runoff models have a significant role to play. 
Due to scarcity of suitable data, modelling the rainfallrunoff process, has not advanced significantly in the Mediterranean region. Even when available, these data are not sufficient to meet the input requirements of existing models. Given these facts, only models that require a limited data input and models that are able to derive unknown / missing parameters via optimisation are suitable for use. In the last decade, automatic and semi-automatic measurements took place and in the last few years high resolution measurements of both rainfall and runoff were recorded.

When there is no gauge at the inlet of a reservoir, the inflow can be estimated from the change in the reservoir level, and therefore the volume, using the stage-volume curve. When the reservoir is full, the excess water flows through the emergency spillway. When the reservoir is full it can be assumed that the catchment is close to saturation and therefore there are fewer unknowns in the runoff estimation equations and knowledge of the catchment soil moisture store, which is usually not available, becomes less crucial. When running a model on an hourly basis, losses due to evaporation can be ignored as it has negligible effect on runoff at that time step. When catchments are mostly bare, with little vegetation cover, rainfall interception also becomes negligible.

The objective of this work is to assess the performance of the newly developed HYDROMED model using data sets of three hill reservoirs in the Mediterranean basin. These reservoirs are El Gouazine and Kamech in Tunisia and Es Sindiany in Syria.

\section{Materials and methods}

Three catchments were selected for testing the HYDROMED model (model structure is given in Part 1 of this paper). A brief description of the sites follows.

\section{EL GOUAZINE, TUNISIA}

The reservoir is located near Kairouan, Ousselita region, Tunisia. It receives runoff water from a catchment area of 1810 hectares. The total volume is $233370 \mathrm{~m}^{3}$, maximum surface area is 9.597 hectares and the average water depth is $2.38 \mathrm{~m}$ (reached $8.32 \mathrm{~m}$ on July 7, 1993 and May 5, 1998). Agricultural lands represent $55 \%$, while woodland represents $35 \%$. Water is abstracted from the reservoir for irrigation. The reservoir was constructed in 1990. More information can be found in Camus et al. (1995) and Albergel (1995, 1998).

\section{KAMECH, TUNISIA}

The reservoir is constructed in the wadi Kamech near Nabeul in the region of Kelibia, Tunisia. It receives runoff water from a catchment area of 247 hectares. Agricultural activity takes place in $75 \%$ of the catchment (cereals, vegetables, etc.) and farmers irrigate tomatoes, peppers, melons etc. by abstracting water from the reservoir. Because of extensive agricultural activity, the reservoir is vulnerable to silting up following heavy storm/flood events. The sediment volume was estimated at $274 \mathrm{~m}^{3}$ following the event of July, 6, 1995 which represents about $2 \%$ of the total volume of the reservoir. The total volume is $142099 \mathrm{~m}^{3}$, maximum surface area is 4.45 hectares and the average water depth is $3.13 \mathrm{~m}$ (reached $8.7 \mathrm{~m}$ following the event of July 6, 1995 and April 30, 1998). The reservoir became operational in 1991. More information can be found in HYDROMED $(1997,1999)$.

\section{ES SINDIANY, SYRIA}

The reservoir was constructed in 1967 in the Homs region ( $\sim 200 \mathrm{Km}$ from Damascus), Syria. It receives runoff water from a catchment area of 340 hectares. Its total maximum volume is $467,030 \mathrm{~m}^{3}$, the maximum water depth is $11.2 \mathrm{~m}$ and the maximum surface area 11.2 hectares. Water is used for irrigating 30 hectares (maize, soya, potatoes, onion). The reservoir is also used for fishing. More information can be found in HYDROMED $(1999,2000)$.

\section{Results and discussion}

\section{EL GOUAZINE, TUNISIA}

From 1993 until 1999, flow over the spillway of El-Gouazine reservoir has occurred only once following the event of September 22, 1995 as shown in Fig. 1.

The spillway flow is important especially for the model calibration process. When the spillway flow takes place, the catchment is assumed to be at, or close to, saturation. In such cases the inflow to the reservoir by surface runoff becomes equal to the outflow of the reservoir as spillway flow. Because the latter is easy to record, it is usually used as a substitute for the surface runoff into the reservoir. Event 3 of September 22, 1995 that generated a spillway flow has been selected for model calibration. The calibration was carried out using the Nash-Sutcliffe criteria as an objective function (Fig. 2). The calibration parameters in terms of minimum and maximum infiltration rate of the catchment, $Z_{\min }$ and $Z_{\max }$, the time lag for runoff flow, $k$ and the Nash-Sutcliffe criterion values are given in Table 1. The goodness of fit expressed by the Nash-Sutcliffe criterion was $98 \%$, which by standard is high as shown in Fig. 2 .

When running the model in simulation mode with input data of Event 1, (October 3, 1994) using the $Z_{\text {min }}, Z_{\text {max }}$ and $\boldsymbol{k}$ parameter values of Event 3, the goodness of fit was $74 \%$ which is still reasonably good. It is quite common that the 
EI - Gouazine Reservoir, Tunisia. Volume and events used in the calibration and simulation

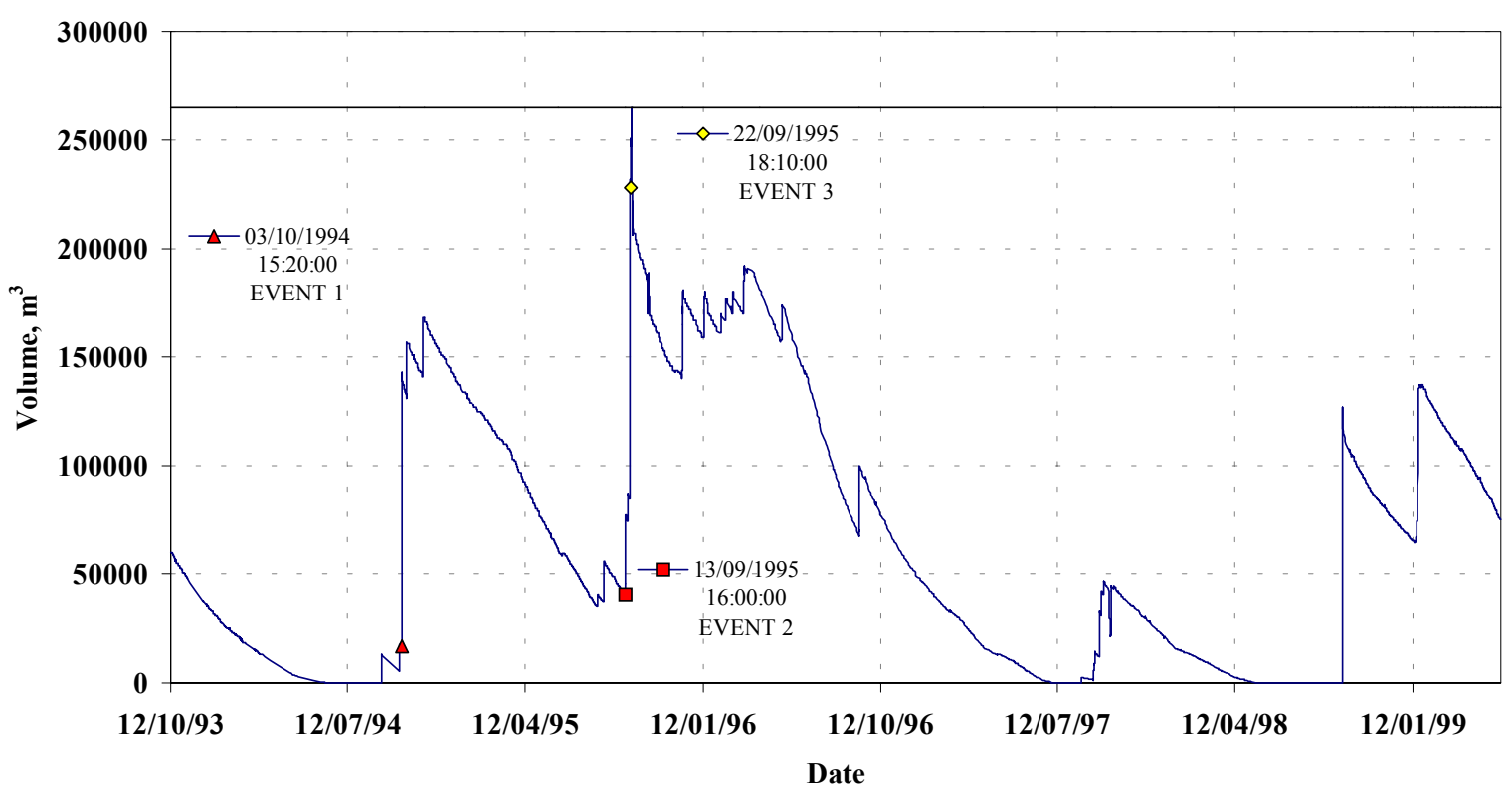

Fig. 1. El Gouazine reservoir volume

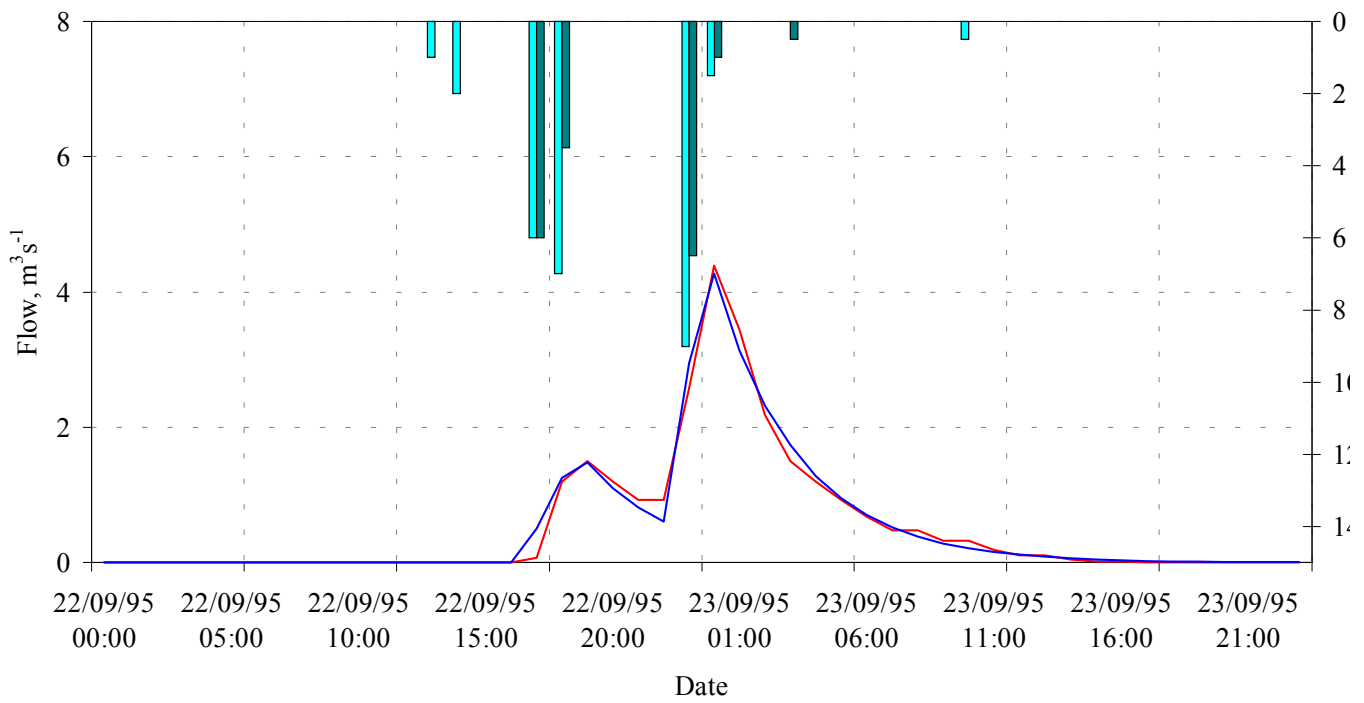

$\square$ Upstream Rainfall $\square$ Reservoir Rainfall — Spillway Runoff — Modelled Runoff

Fig. 2. Calibration of Event 3

Table 1. El-Gouazine Reservoir: calibration and simulation results

\begin{tabular}{lllllll}
\hline $\begin{array}{l}\text { Event } \\
\text { number }\end{array}$ & Date & $\begin{array}{l}\text { Calibration, } \boldsymbol{C} \\
\text { Simulation, } \boldsymbol{S}\end{array}$ & $\begin{array}{l}\text { Zmin, } \\
m m h^{-1}\end{array}$ & $\begin{array}{l}\text { Zmax, } \\
m m h^{-1}\end{array}$ & $\begin{array}{l}k \text { (time lag), } \\
h\end{array}$ & $\begin{array}{l}\text { Nash-Sutcliffe } \\
\text { Criterion }\end{array}$ \\
\hline 3 & $22-23 / 9 / 95$ & $\mathbf{C}$ & 4.31 & 7.90 & 3.35 & 0.98 \\
1 & $3-4 / 10 / 94$ & $\mathbf{S}$ & 4.31 & 7.90 & 3.35 & 0.74 \\
2 & $13-14 / 9 / 95$ & $\mathbf{S}$ & 4.31 & 7.90 & 3.35 & 0.55 \\
All $(1,2,3)$ & $3 / 10 / 94-14 / 9 / 95$ & $\mathbf{S}$ & 4.31 & 7.90 & 3.35 & 0.67 \\
\hline
\end{tabular}




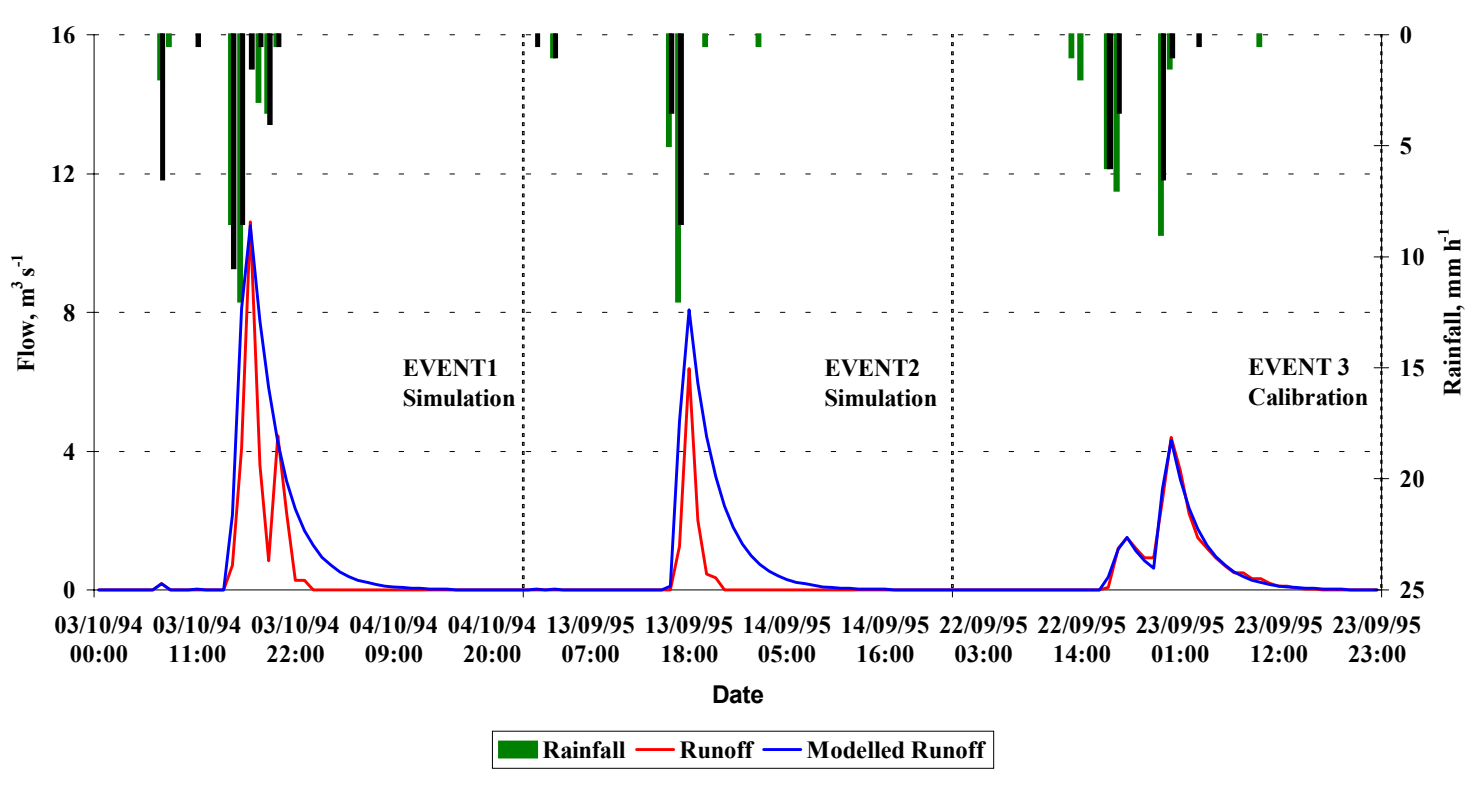

Fig. 3. Simulated and observed runoff flow using Event 3 calibration parameters

goodness of fit obtained from the simulation is less than that obtained by calibration. The simulation using calibration parameters of Event 3 and input data of Event 2, September 13, 1995 did not produce a high value for goodness of fit (55\%) when compared with Event 1 (74\%). The simulation was also carried out for the whole period from October 3, 1994 to September 14, 1995 using calibration parameters of Event 3. The overall goodness of fit was $67.3 \%$ as shown in Fig. 3. This is still acceptable given that these events did not generate spillway flow and the flow is calculated from changes in the water volume in the reservoir. The latter is prone to uncertainties stemming from the accuracy of the depth -surface area relationship, the siltation, losses by evaporation and un-recorded releases.

\section{KAMECH RESERVOIR, TUNISIA}

The reservoir volume and rainfall distribution for the 19951999 period indicates 4 events (Fig. 4). Event 2 managed to generate spillway flow while other events have resulted in increasing the reservoir's volume without exceeding the maximum storage level.

The calibration of Events 1, 2, 3 and 4 was carried out and the Nash-Sutcliffe values were found to be $91 \%, 89 \%$, $70 \%$ and $62 \%$ for Events 1 to 4 respectively. The parameter values showed some variability between the events as given in Table 2. When the calibration parameters of each event were used to simulate the whole period, the highest NashSutcliffe value was obtained using parameters of Event 3 (76\%). Figure 5 shows the simulated flow using calibration

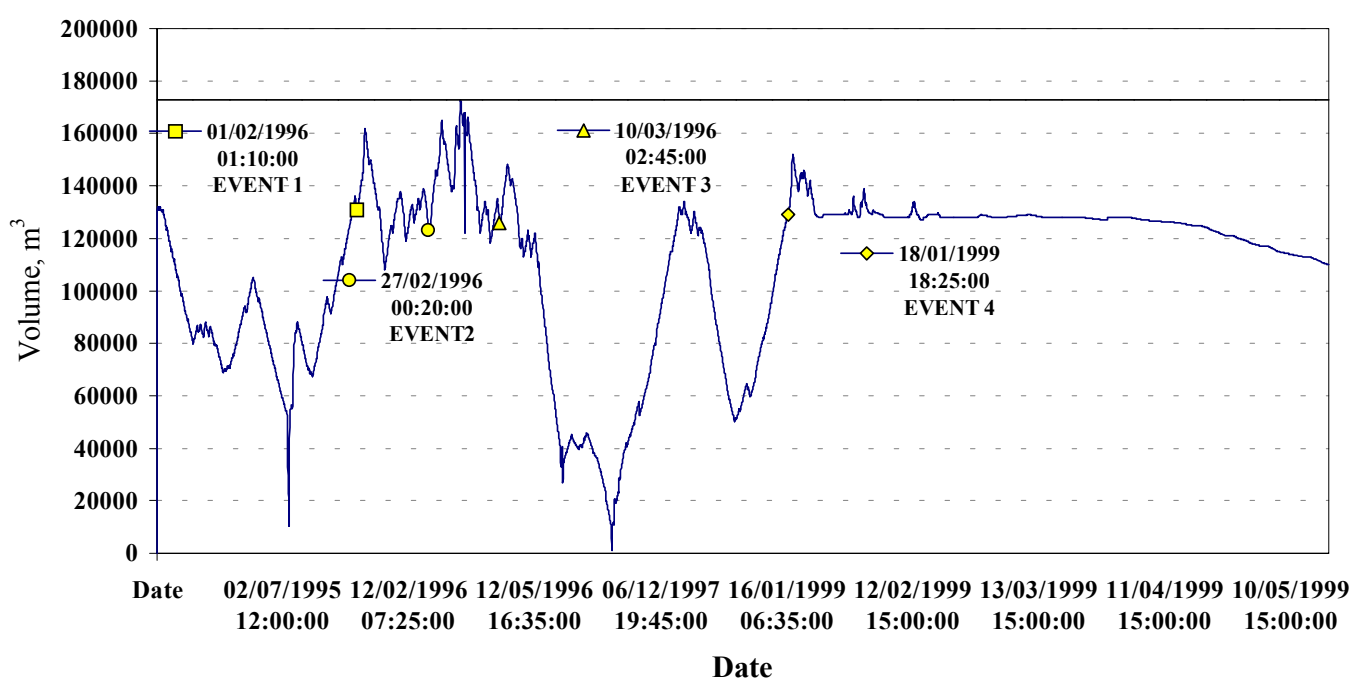

Fig. 4. Kamech Reservoir's volume 
Table 2. Kamech Reservoir. Calibration and simulation results

\begin{tabular}{|c|c|c|c|c|c|c|}
\hline $\begin{array}{l}\text { Event } \\
\text { number }\end{array}$ & Date & $\begin{array}{l}\text { Calibration, } \boldsymbol{C} \\
\text { Simulation, } \boldsymbol{S}\end{array}$ & $\begin{array}{l}\text { Zmin, } \\
\mathrm{mm} \mathrm{h}^{-1}\end{array}$ & $\begin{array}{l}\operatorname{Zmax} \\
\operatorname{mm} h^{-1}\end{array}$ & $\begin{array}{l}k \text { (time lag), } \\
h\end{array}$ & $\begin{array}{l}\text { Nash-Sutcliffe } \\
\text { Criterion }\end{array}$ \\
\hline 1 & $1-2 / 2 / 96$ & $\mathbf{C}$ & 3.35 & 8.07 & 4.56 & 0.91 \\
\hline 2 & $27-29 / 2 / 96$ & $\mathbf{C}$ & 1.51 & 5.24 & 3.13 & 0.89 \\
\hline 3 & $10-11 / 3 / 96$ & $\mathrm{C}$ & 2.26 & 2.35 & 6.21 & 0.70 \\
\hline 4 & $18-20-1-99$ & C & 0.01 & 6.70 & 10.21 & 0.62 \\
\hline All & $1 / 2 / 96-1 / 2 / 99$ & $\begin{array}{l}\mathbf{S} \text { using event } 2 \\
\text { parameters }\end{array}$ & 1.51 & 5.24 & 3.13 & 0.63 \\
\hline All & $1 / 2 / 96-1 / 2 / 99$ & $\begin{array}{l}\mathbf{S} \text { using event } 3 \\
\text { parameters }\end{array}$ & 2.26 & 2.35 & 6.21 & 0.76 \\
\hline
\end{tabular}

parameters of Event 2 while Fig. 6 shows the simulated flow using calibration parameters of Event 3. Although Event 2 calibration had a high Nash-Sutcliffe value compared with Event 3, the simulation of the whole period had a better Nash-Sutcliffe value when using calibration parameters of Event 3. It is also surprising that the whole period simulation had even a higher value for Nash-Sutcliffe when compared with the Event 3 calibration.

Generally, the Nash-Sutcliffe values were relatively high; however, a better simulation can be expected when a longer flow record becomes available. The variations noticed here could be attributed to unrecorded releases for irrigation and other purposes.

ES-SINDIANY RESERVOIR, SYRIA

The available records showed that during the period between 1997 and 1999 a reasonable number of events took place but apart from Event 1, the majority were too small. The changes in the reservoir volume are shown in Fig. 7.

The calibration of the events was carried out and the highest Nash-Sutcliffe value was associated with Event 1, being $85 \%$, and Event 2, being $72 \%$, as shown in Table 3 .

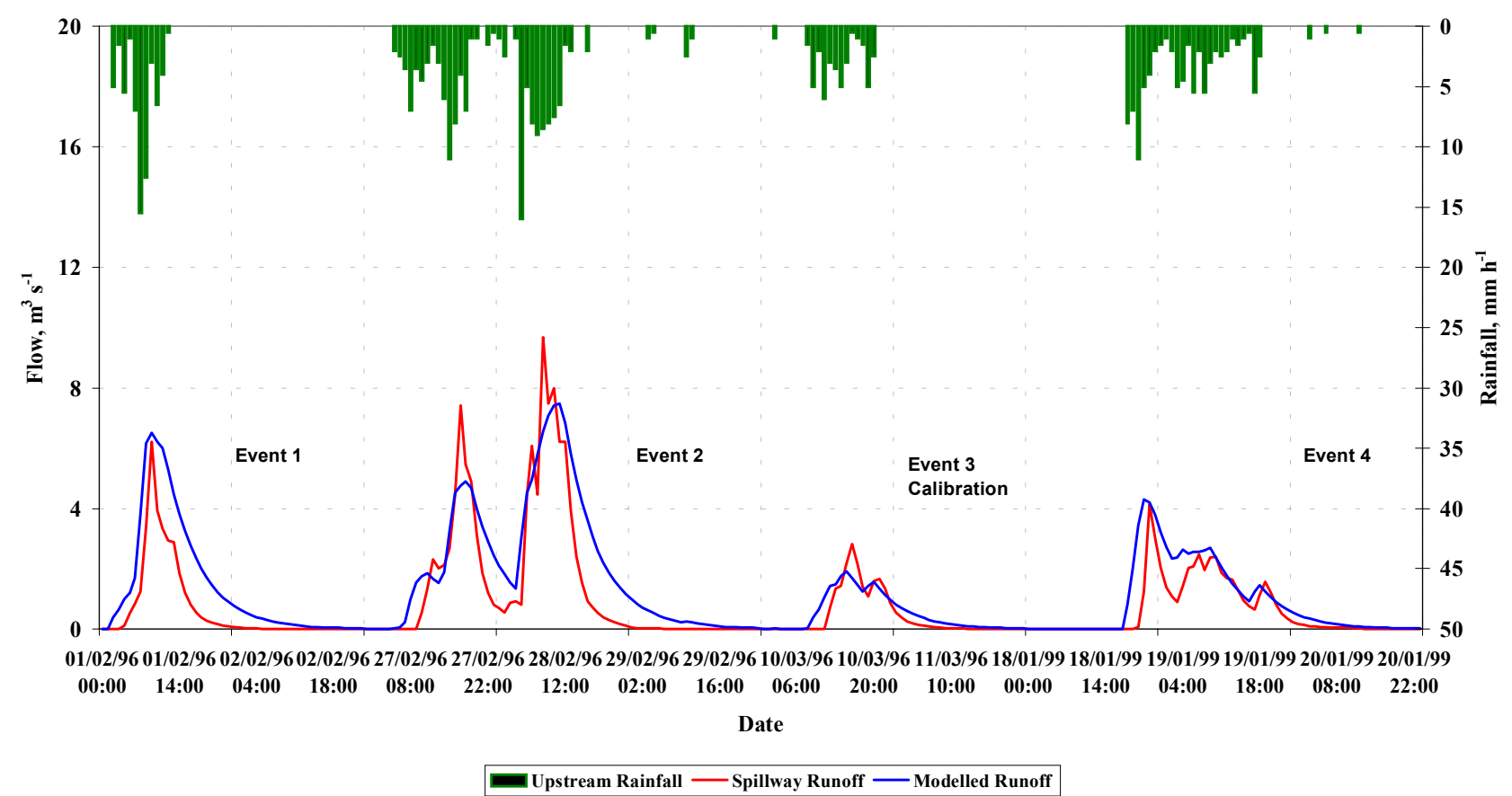

Fig. 5. Simulated and observed runoff flow using Event 2 calibration parameters. 


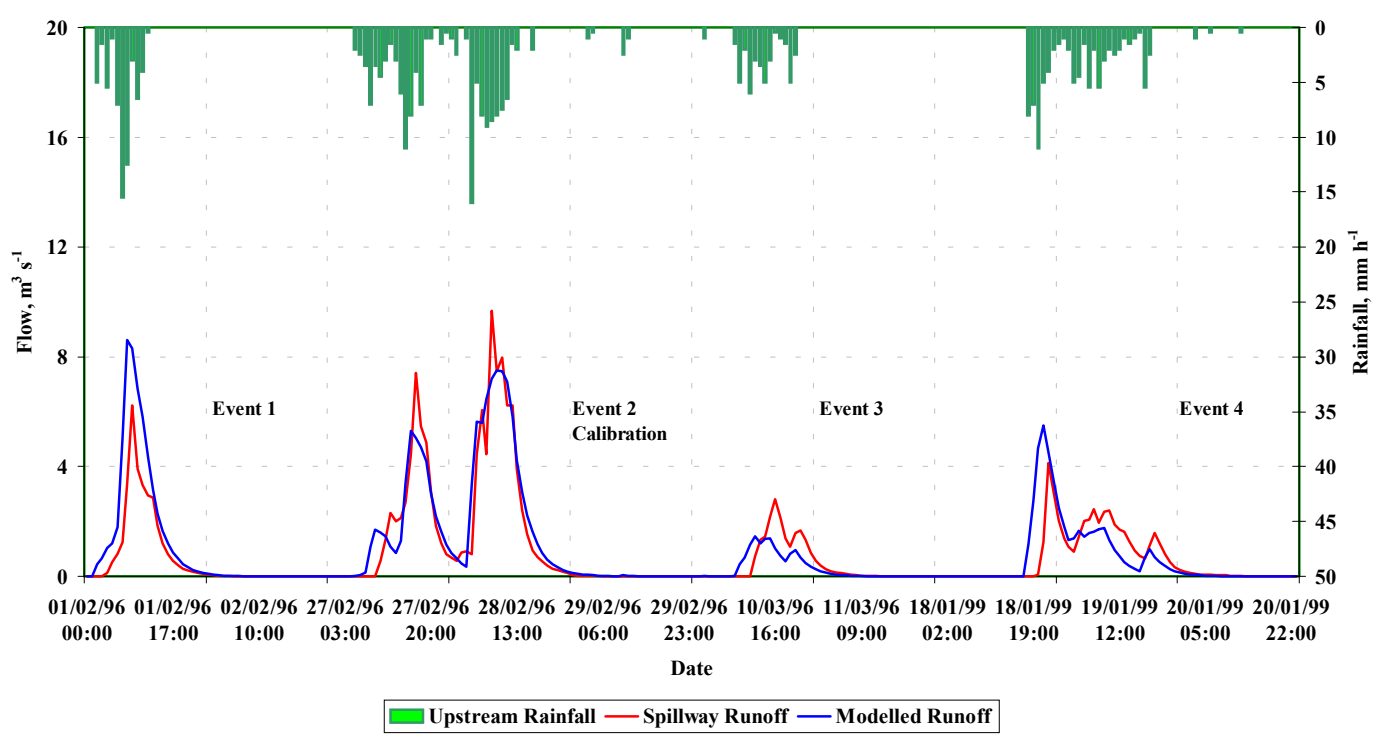

Fig. 6. Observed and simulated runoff flow using calibration parameters of Event 2.

Figure 8 shows the calibration of Event 1 . The simulation of the whole period using the calibration parameters of Event 2 produced the highest Nash-Sutcliffe value as given in Table 3 and shown in Fig. 9.

The Nash-Sutcliffe value obtained for the whole period was $46 \%$, which is not high. It is known that releases for irrigation and other usage were not recorded, at the same time a release valve usually becomes operational when the water level reaches its maximum and the spillway flow starts. It is a precautionary measure taken to protect the dam.
Naturally, this measure does not help in providing the modelling work with accurate flow values.

\section{General discussion}

Generally, the results obtained from the three catchments indicated that the HYDROMED model is capable of reproducing the runoff volume in all of the studied sites. In calibrating single events, the model performance was quite high as indicated by the Nash-Sutcliffe criterion for

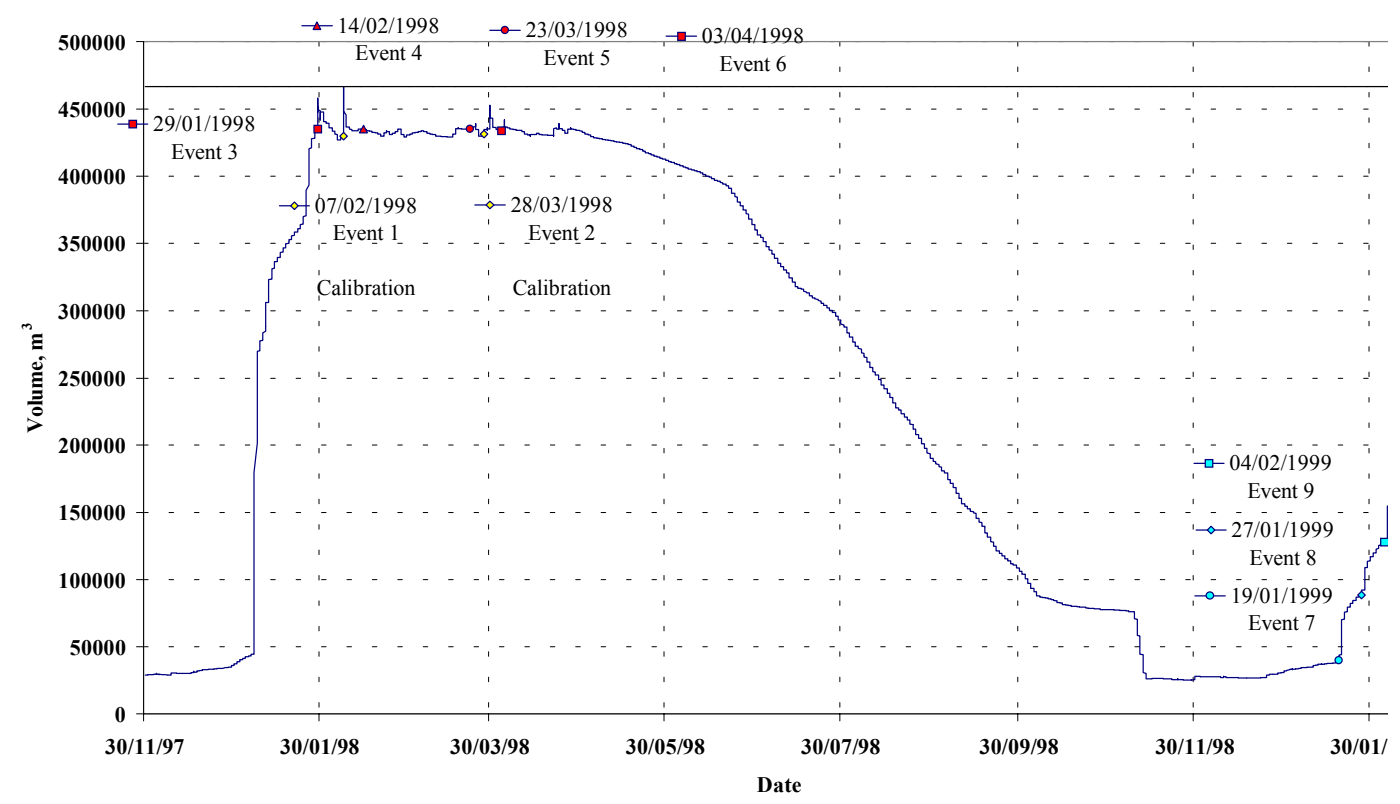

Fig. 7. Es Sindiany Reservoir volume 
Table 3. Es Sindiany Reservoir. Calibration and simulation results.

\begin{tabular}{llllllc}
\hline $\begin{array}{l}\text { Event } \\
\text { number }\end{array}$ & Date & $\begin{array}{l}\text { Calibration, } \boldsymbol{C} \\
\text { Simulation, } \boldsymbol{S}\end{array}$ & $\begin{array}{l}\text { Zmin, } \\
m m h^{-1}\end{array}$ & $\begin{array}{l}\text { Zmax, } \\
m m h^{-1}\end{array}$ & $\begin{array}{l}k \text { (time lag), } \\
h\end{array}$ & $\begin{array}{c}\text { Nash-Sutcliffe } \\
\text { Criterion }\end{array}$ \\
\hline 1 & $7-10 / 2 / 98$ & $\mathbf{C}$ & 1.75 & 17.55 & 4.87 & 0.85 \\
2 & $28 / 2 / 98$ & $\mathbf{C}$ & 1.69 & 3.08 & 13.64 & 0.72 \\
\hline
\end{tabular}

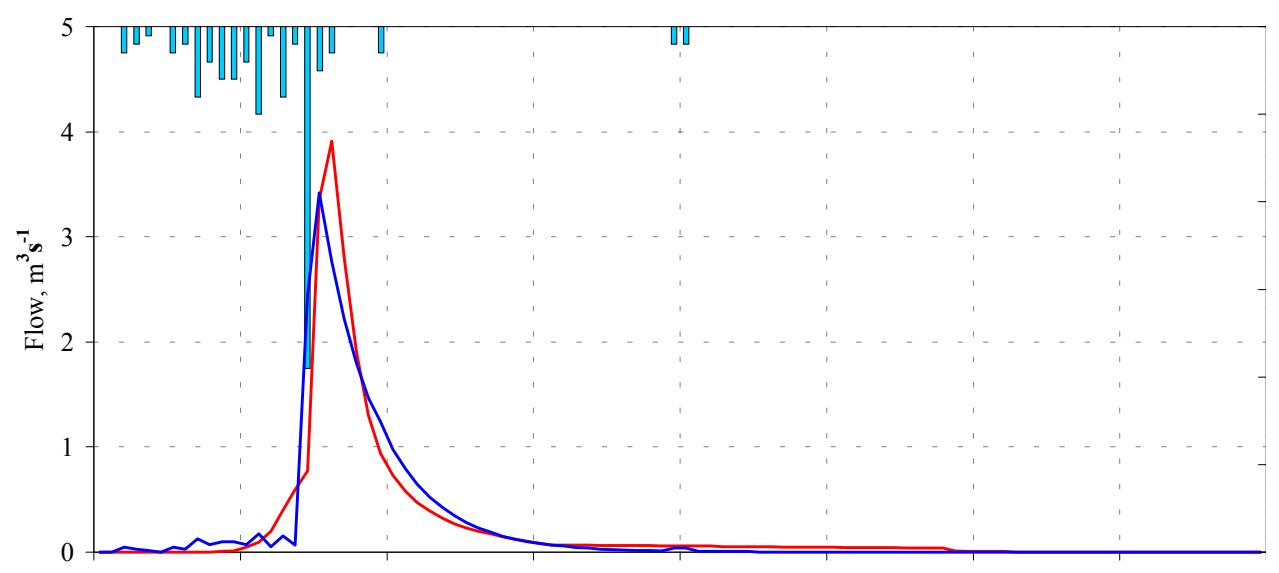

07/02/98 07/02/98 07/02/98 08/02/98 08/02/98 08/02/9809/02/98 09/02/98 09/02/98 10/02/98 10/02/98 10/02/98

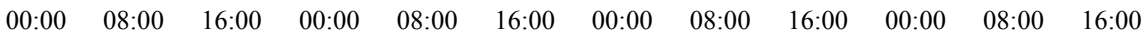

Date

$\square$ Upstream Rainfall — Spillway Runoff - Modelled Runoff

Fig. 8. Calibration of Event 1

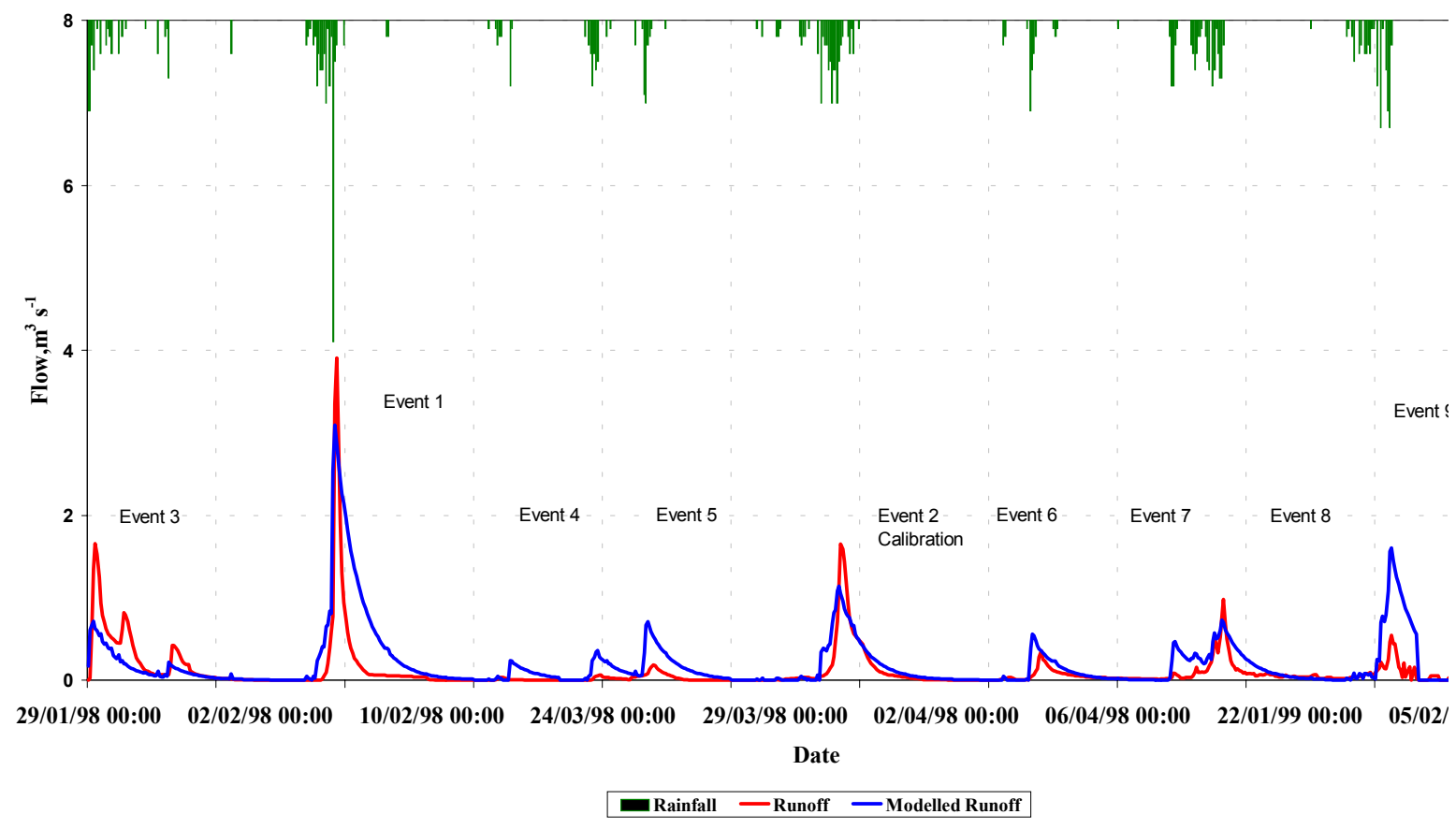

Fig. 9. Simulated and observed runoff flow using Event 3 calibration parameters. 
goodness of fit. In some events this value was as high as $98 \%$. In simulation mode, the highest Nash-Sutcliffe criterion value for the whole time series was close to $70 \%$.

The three sites studied have different characteristics that might explain some of the results obtained by simulation. It is known that El Gouazine catchment is susceptible to erosion and the reservoir is susceptible to siltation. This could have an impact on the accuracy of volume estimation. Recently, some dykes were constructed to retain water and to prevent silt from entering the reservoir. Recent information indicates that water retained by the dikes is approximately the same as the amount that enters the reservoir during an event. Further modelling work to compare the calibration parameters prior to the construction of the dykes with the calibration parameters after building the dykes is planned. It has also been reported that three raingauges are now in place. Soil moisture measurements have also started.

The geology of the Kamech catchment indicates that the catchment consists of two alternating layers of sandstone and clay, which are positioned at an angle. This phenomenon affects the catchment in two different ways. On one side of the catchment the soil is more susceptible to erosion and contributes most of the silt in the reservoir. On the other side storage of water under the surface sometimes cracks the sandstone allowing the water to emerge on the surface and contribute to the surface runoff. This contribution to the flow can take place at any unpredictable time and could continue for two to three days after the event so, with this catchment, the calibration should be carried out very carefully. It requires good book-keeping of events and what follows these events in terms of additional and unexpected contribution. On the sides of the catchment during the dry periods big cracks in the soil may give deceptive measurements. As a rough estimate by IRD (Institute of Research and Development, French Mission in Tunisia) the soil can retain about $100 \mathrm{~mm}$ of rain when the cracks are open whilst when they are closed it can retain only about $6 \mathrm{~mm}$. Recently, soil moisture measurement collection has begun and data will soon become available.

In Es Sindiany, the numerous recorded events should have given us enough information to calculate the optimum rainfall-runoff model parameters, however, the model simulation results were slightly discouraging. It is common practice in this reservoir, to open the release valve when a flood event occurs and the reservoir fills up to its maximum capacity in order to avoid overflow and possible breach of the dam. The water released by the discharge valve could interfere and cause inaccuracy in the spillway discharge measurements. This could explain why the model did not perform as well as the other reservoirs.
In semi-arid regions, the major problem that will always face modellers is the quality of the inflow data. At present, unless the reservoir spillway is spilling, the only way of estimating the reservoir inflow is by looking at the change in the reservoir level. Because of wind, lag and resolution of the depth recorder, the inflow cannot be quantified accurately enough to calibrate rainfall-runoff models. Subsequently, hydrographs deduced from changes in the volume are not expected to give very accurate simulation results. In a heavy rainfall event there is likely to be some associated wind reservoir surging, which makes the estimation of the inflow more difficult. Moreover, most of the reservoirs are equipped with only one raingauge.

Generally, the results of this work highlight the need for more recording instrumentation, more raingauges and long term records with large numbers of significant events that are able to generate spillway flow to obtain more consistent and reliable parameter values. It also highlights the need for more accurately recorded releases for irrigation and other uses. Generally, the results are encouraging and more tests on these three and other sites, are planned.

\section{Conclusions}

In general, the results obtained from El-Gouazine, Kamech and Es Sindiany catchments confirmed that the HYDROMED model is capable of reproducing the runoff volume in all of the three sites. In calibrating single events, the model performance was high as indicated by the NashSutcliffe criterion for goodness of fit. In some events this value was as high as $98 \%$. In simulation mode, the highest Nash-Sutcliffe criterion value for the whole time series was close to $70 \%$ in the El-Gouazine and Kamech catchments, and close to $50 \%$ in Es Sindiany catchment. Given the sparse information available, especially on the unrecorded releases in the three catchments, the hydrological impact of site geology (e.g. Kamech), unaccounted operator intervention during the spillway flow (e.g. Es Sindiany) and other factors unaccounted for (e.g. siltation, evaporation, etc.), these results are very encouraging. Moreover, these results highlighted the need for more recording instrumentation, more raingauges and long term records with a large number of significant events that are able to generate spillway flow to obtain more consistent and reliable parameter values. It also highlighted the urgent need for more accurately recorded releases for irrigation and other uses. Since these results are encouraging, plans for more tests on those three catchments, as well as other sites have been drawn up. 


\section{Acknowledgements}

The HYDROMED model is part of the HYDROMED project, $50 \%$ funded by the European Union, EU and 50\% funded by the Natural Environment Research Council, NERC, UK. The authors would like to thank all partners of the HYDROMED project, ACSAD, Syria, INGREF, Tunisia, IAV Morocco for their cooperation.

\section{References}

Albergel. J., 1995. Annuaire hydrologique des lacs collinaires, IRD Report, Tunisia.

Albergel. J., 1998. Annuaire hydrologique des lacs collinaires, IRD Report, Tunisia.

Camus, H., Albergel, J., Guiguen, N. and Ben Younes, M., 1995. Note sur L' envasement de lacs collinaires en zone semi-arid tunisienne (2), IRD Report, Tunisia.

HYDROMED., 1997. $1^{\text {er }}$ Rapport d'avancenment Hydromed. ERBIC 18 CT 960091. Report for the EU, IRD Report, Tunisia.

HYDROMED., 1999. Cinquieme Rapport d'avancement Hydromed. ERBIC 18 CT 960091. Report for the EU, IRD Report, Tunisia.

HYDROMED., 2000. Sixieme Rapport d'avancement Hydromed. ERBIC 18 CT 960091. Report for the EU, IRD Report, Tunisia. 